\title{
Complete Transposition of the Great Vessels in Infancy with Reference to Palliative Surgery
}

\author{
A. W. VENABLES \\ From the Royal Children's Hospital, Melbourne, Victoria, Australia
}

It is necessary to confine discussion of complete transposition of the great vessels to individuals in whom the aorta arises wholly from the right ventricle and the pulmonary artery arises wholly from the left ventricle in association with normal atrio-ventricular valves and with an interventricular septum. This definition (Elliott et al., 1963) excludes transposition complicating tricuspid and mitral atresia and anatomical single ventricle, in which the hæmodynamic disturbance differs from that to be considered.

The prognosis of untreated complete transposition depends largely on the communications that persist between the pulmonary and systemic circuits and the effective pulmonary flow that is achieved through them. Effective pulmonary flow may be defined as the volume of systemic venous blood that is exchanged for pulmonary venous blood and represents the amount of systemic venous blood that passes to the lungs for oxygenation (Shaher, 1964). Normally transfer of blood is restricted and effective pulmonary flow is small, though actual pulmonary flow is often substantially increased (Shaher, 1964). The outlook in transposition is usually poor with early death from hypoxia possibly complicated by heart failure. Keith, Rowe, and Vlad (1958) reported 86 per cent dead at 6 months. Long-term survival appears to be potentiated by significant ventricular septal defect complicated by pulmonary stenosis or pulmonary vascular obstruction (Noonan et al., 1960). Significant atrial septal defects are uncommon, but Blalock and Hanlon (1950) considered that they also potentiated survival, and therefore advocated surgical creation of such defects. Although Shaher (1963) disputed the significance of the conclusions of Blalock and Hanlon, surgical creation of atrial septal defects appears to alter the prognosis significantly.

Received April 12, 1965.
This paper is based on a series of 53 infants with complete transposition of the great vessels, who were seen at the Royal Children's Hospital, Melbourne, in the four years 1960 to 1963 . Attempts were made to create atrial septal defects in 30 infants. Of these infants, 12 were alive in December 1964 with follow-up periods of from 14 months to 4 years. Their current clinical state is reported.

\section{SUBJECTS}

During the four years 1960 to 1963,53 infants (33 male and 20 female) presented with cyanotic heart disease, proven by investigation or by necropsy to be complete transposition of the great vessels. Of these, 36 infants presented in the first week of life, 15 actually in the first 48 hours, but 6 infants were not seen until aged 3 months or older. The oldest was aged 8 months when referred. Virtually all exhibited marked cyanosis with associated dyspnoea. Evidence of cardiac failure was considered to be present in 28 of them. Murmurs were most frequently absent or soft, but loud systolic murmurs were present in a few. Radiological findings varied somewhat. Most commonly there was obvious cardiac enlargement with pulmonary plethora, but in some, particularly infants seen in the early neonatal period, the heart was at most bulky and there was no pulmonary plethora. In some of these further radiological examination revealed the development of obvious cardiac enlargement and plethora. Electrocardiograms showed right ventricular preponderance or hypertrophy with upright $T$ waves in the right chest leads in a significant number.

There were 17 infants who died without catheterization or angiocardiography: some were moribund when first seen, and others died while awaiting study. Ages at death are shown in Fig. 1a. The diagnosis of transposition was confirmed in all at necropsy. 


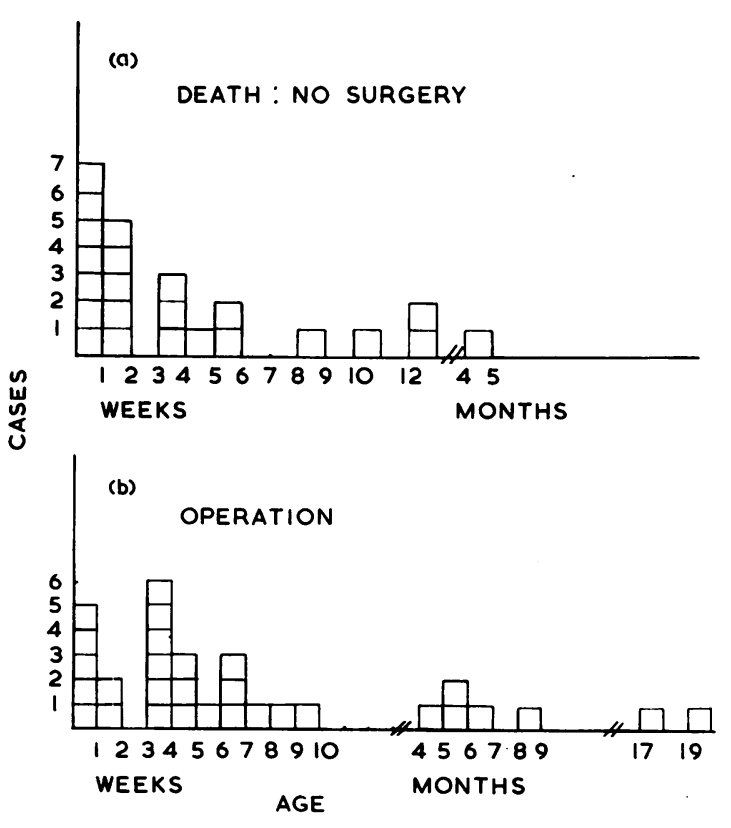

FIG. 1a.-Ages of patients dying without operation. FIG. 1b.-Ages of patients at operation (creation of atrial septal defect).

Special investigations were performed in 36 infants. These studies ranged from simple venous angiography in some who were seen early in the period, to formal cardiac catheterization with multiple selective angiocardiography. Selective right ventricular angiocardiography was performed in 25 infants, and 13 of them also had selective left atrial injections. The left ventricle was entered via the left atrium in 10 infants. In 2 , subsequently proven to have significant ventricular septal defects, the pressures in right and left ventricles were equal. In 2 others without ventricular septal defects at necropsy, catheterization at 2 days of age revealed systolic pressures in the right and left ventricles of approximately 55 and $45 \mathrm{~mm}$. $\mathrm{Hg}$, respectively. In the remainder left ventricular systolic pressure ranged between one- and two-thirds of the corresponding right ventricular pressure. None of these infants have conclusive clinical or investigatory evidence of ventricular septal defect: 5 are alive, while the one who died did not have a post-mortem examination. The pulmonary artery was entered through a ventricular septal defect on three occasions. No constant pattern of atrial shunting was detected.

Surgical procedures aimed at creating an atrial septal defect were performed in 30 of the 36 infants who were investigated. The remaining 6 infants died: one from bilateral renal vein and inferior vena caval thrombosis approximately one week after catheterization (Venables and Hiller, 1963, Case 17), the findings at the time of investigation suggesting that thrombosis had commenced before study; one following angiography with diffuse cerebral venous thrombosis and femoral artery thrombosis; one suddenly from unknown causes on the night of the study, permission for necropsy being refused; one very ill infant with a hypoplastic right ventricle and an interrupted aortic arch sustained severe intramyocardial extravasation of radiopaque dye, which probably hastened death; parental refusal of operation for one infant was accepted because of poor social background; and the remaining infant, who had less than usual cyanosis, and also at 2 months of age had been shown to have a large ventricular septal defect, a patent ductus, and increased pulmonary flow, suffered episodic deterioration, thought to be due to left ventricular failure, and died at 3 months.

The 30 surgical procedures comprised three attempts to create atrial septal defects under vision during inflow occlusion and 27 procedures of Blalock-Hanlon type (Blalock and Hanlon, 1950; Baffes, 1962; Ochsner et al., 1961). Of these 30 operations, 27 were performed by Mr. G. W. Westlake, and the remaining 3 by Mr. P. G. Jones. The indication for operation was the presence of substantial central cyanosis, independent of the nature of any communications which had been demonstrated by investigation. Many of these infants were critically ill, but some had settled into a fairly stable state despite the degree of cyanosis and disability present. In some, operation was delayed because of uncertainty of its value and of the risks involved. The only infant in whom creation of an atrial septal defect was not considered advisable was the patient described in the previous paragraph who had mild cyanosis and died at 3 months of age after a course apparently associated with left ventricular failure. Pulmonary artery banding was not attempted in this infant, though in retrospect it would have been appropriate. Creation of atrial septal defects under inflow occlusion was abandoned in favour of the Blalock-Hanlon technique after 3 attempts because of two episodes of coronary air embolism and one of accidental cardiac perforation.

The over-all outcome of surgery is shown in Table I. There were 11 deaths which appeared to be related to the procedure. The majority of these were associated with pulmonary complications comprising collapse, pneumonia, and hæmorrhage. In 2 infants in whom there was prolonged occlusion of the right pulmonary vessels, there was infarction of 
TABLE I

OPERATIONS TO CREATE ATRIAL SEPTAL DEFECTS (1960-63)

\begin{tabular}{llllll|r}
\hline Inflow occlusion & $\ldots$ & $\ldots$ & $\ldots$ & $\ldots$ & $\ldots$ & 3 \\
Blalock-Hanlon $\ldots$ & $\ldots$ & $\ldots$ & $\ldots$ & $\ldots$ & $\ldots$ & 27 \\
\hline & & & & & Total & 30 \\
\hline $\begin{array}{l}\text { Operative deaths } \\
\text { Delayed death (inadequate defect) } \\
\text { Delayed death (post-operative improvement) }\end{array}$ & $\ldots$ & $\ldots$ & $\ldots$ & 11 \\
$\begin{array}{l}\text { Death following further operation } \\
\text { Current survivors }\end{array}$ & $\ldots$ & $\ldots$ & $\ldots$ & $\ldots$ & $\ldots$ & $\mathbf{4}$ \\
\hline
\end{tabular}

the right lung. There was one instance of heart block leading to cardiac arrest and death on the day following surgery.

In 4 infants there was no change in clinical status, suggesting that no effective defect had been created. These infants died at intervals ranging between 5 weeks and 16 months after operation. No defect was found in one, and in another there was a defect $2.5 \mathrm{~mm}$. in diameter. Necropsy was not performed in the other two infants.

Three infants who were improved by operation subsequently died: one from respiratory infection 2 months after operation; another at home from unknown cause $3 \frac{1}{2}$ months after operation; and the third child at the age of $3 \frac{1}{2}$ years following openheart surgery which had been performed to achieve total physiological correction. There are therefore 12 children currently alive of 13 original long-term survivors who were improved by operation.

The survivors have an age range from 14 months to just over 4 years with follow-up periods of 14 months to 4 years as of December 31, 1964. All are improved and apparently stable. Current status varies from mild cyanosis with mild polycythæmia in most to at least moderate cyanosis with substantial polycythæmia in some (Fig. 2). The result may be classified as good in most cases. One patient must be regarded as unsatisfactory though an improved survivor. This child, now aged $2 \frac{1}{2}$ years, has remained at least moderately cyanosed with considerable limitation of exercise tolerance. She has a hæmoglobin level of $18.8 \mathrm{~g} . / 100 \mathrm{ml}$., a red cell count of 7.9 million/c.mm., and an earpiece saturation of only 66 per cent at the age of $2 \frac{1}{2}$ years. Hæmoglobin levels are greater in the older children (Fig. 2), the highest figure being $21.6 \mathrm{~g} . / 100 \mathrm{ml}$. in a child of $2 \frac{1}{2}$ years. Earpiece oxygen saturations in the other patients correspond with the degree of cyanosis, the highest level recorded being 92 per cent. The range of occasional isolated observations is 72 to 92 per cent. The majority of the children are in fact making essentially normal progress and have only mild disability. One patient who has returned to another State is claimed by his parents to be too well to attend a pædiatrician for review. One other patient is being followed up elsewhere and is known to have only mild cyanosis. Radiological studies have indicated current stability of relative heart size and pulmonary vascularity. In 2 patients heart size decreased considerably soon after operation, apparently because of control of cardiac failure. Two patients have hemipareses. In one, the weakness was present before operation and probably represents a residue of birth injury, but in the other case hemiparesis developed suddenly at the age of 18 months, operation having been performed at 3 weeks of age. This child has substantial cyanosis and polycythæmia.

Two patients have had repeat cardiac catheterization approximately $3 \frac{1}{2}$ and 4 years after operation. One had bidirectional shunting at atrial level with left and right ventricular pressures of $40 / 0$ and $88 / 0$ $\mathrm{mm} . \mathrm{Hg}$, respectively. There was no evidence of any other defect. Complete repair of Senning type was performed using a pericardial patch to divert venous inflow, but operation was followed by death from intractable intrathoracic hæmorrhage unrelated to the repair itself. The second patient reinvestigated has a large left-to-right shunt at atrial level and a corresponding aorto-pulmonary shunt through a large patent ductus. Pulmonary flow has not been measured directly but appears to be much increased so that one may deduce that the pulmonary vascular resistance is not sufficiently increased to contraindicate further operation. This infant has developed an early diastolic murmur apparently due to pulmonary regurgitation resulting from dilatation of the pulmonary trunk.

The third patient who has had follow-up catheterization is the child of $2 \frac{1}{2}$ years of age described as

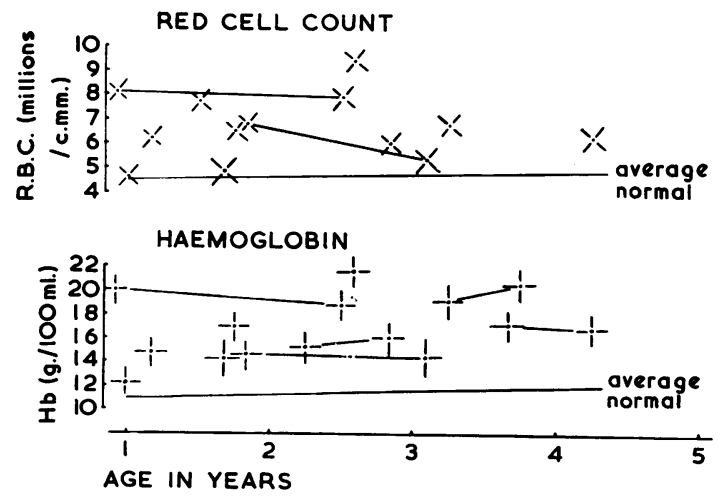

FIG. 2.- Red cell count and hæmoglobin levels in surviving patients with effective surgical atrial septal defect. 
unsatisfactory. This child has bidirectional shunting at atrial level through the surgical defect and at ventricular level through a large ventricular septal defect. Ventricular pressures are balanced; the pulmonary flow appears to be less than systemic flow, and there is no evidence of pulmonary stenosis.

One patient has had recurrent episodes of paroxysmal atrial tachycardia with rates of approximately 300 a minute. These attacks have been well tolerated, and have not precipitated cardiac failure. Several patients have sustained repeated respiratory tract infections.

Figure $1 \mathrm{~b}$ compares the age at death of those patients who were not operated on with the age at which operation was performed. This shows that the patients submitted to operation were on the whole older than those who did not have operations. Cardiac failure was thought to be present in 13 of the 30 patients who were operated on compared to 15 of the 23 who were not. Ventricular septal defects ranging from $2 \mathrm{~mm}$. to approximately $8 \mathrm{~mm}$. in diameter were present in 8 of 13 necropsy specimens from the surgical group and were indicated by investigatory findings in 4 others. Ventricular septal defects were demonstrated in 5 of the 21 necropsies performed on the 23 patients who did not have operation. Four of the defects in the latter group were large: one of these was, however, in the mildly cyanosed patient already discussed, who was thought to have left ventricular failure.

There was evidence of at least minor duct patency in 28 of the total of 34 necropsy specimens. The foramen ovale was patent, sometimes widely, in 20 of the 21 specimens in which no operation had been performed on the atrial septum. Additional significant anomalies detected are shown in Table II.

TABLE II

ADDITIONAL CARDIOVASCULAR ANOMALIES*

\begin{tabular}{|c|c|c|c|}
\hline Anomalies & & & No. \\
\hline 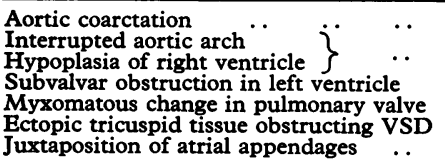 & $\begin{array}{l}\cdots \\
\cdots \\
\cdots \\
\cdots \\
\cdots\end{array}$ & $\begin{array}{l}\cdots \\
\cdots \\
\cdots \\
\cdots \\
\cdots\end{array}$ & $\begin{array}{l}1 \\
1 \\
1 \\
1 \\
1 \\
1\end{array}$ \\
\hline
\end{tabular}

* Other than patent foramen ovale, atrial septal defect, ventricular septal defect, and patent ductus arteriosus.

\section{Discussion}

Diagnosis. Complete transposition of the great vessels can be diagnosed with fairly considerable accuracy when deep cyanosis is associated with pulmonary plethora. The presence of at least normal right ventricular activity in the electrocardiogram is of course obligatory. Occasionally these findings may be due to other conditions which should be identified by special investigation provided the findings are accurately interpreted. During the period under consideration, however, one newborn infant with double outlet right ventricle without pulmonary stenosis but with deep cyanosis (Venables and Campbell, 1966) was subjected to a Blalock-Hanlon procedure because of erroneous interpretation of a venous angiogram which on review indicated the correct diagnosis. Investigation is indicated in individuals with severe cyanosis and plethora, and a diagnosis of complete transposition of the great vessels should if possible not be made until both the origin of the aorta from the right ventricle and the origin of the pulmonary trunk from the left ventricle have been demonstrated conclusively.

In some infants there may not be significant cardiac enlargement and plethora. This may be due to the presence of significant pulmonary stenosis, but is also seen in transposition if radiographs are obtained before the postnatal circulatory adjustments have stabilized. Significant pulmonary stenosis will lead to dry lung fields, while in its absence the lungs may appear normal. The occurrence of relatively normal radiological appearances in young newborns with complete transposition is well recognized (Keith et al., 1958). Transposition should be suspected in newborns who have deep cyanosis and relatively normal radiological appearances and is in fact much more common in these circumstances than methæmoglobinæmia. If the infant survives further radiographs are likely to show development of cardiac enlargement and plethora. The cardiac and mediastinal contour is variable (Astley and Parsons, 1952), as might be expected from the differing anatomical relations of aorta and pulmonary trunk (Elliott et al., 1963). The appearances may be helpful in diagnosis, particularly if the pulmonary trunk lies behind the aorta and there is a narrow pedicle, or if convexity of the aorta at the left border of the mediastinum is present, or a central position of the pulmonary trunk is recognizable. Auscultatory signs are of no value in primary diagnosis but may be relevant to consideration of associated abnormalities. Phonocardiographic studies have been reported by Wells (1963).

Investigation to confirm the diagnosis of transposition should be performed without delay as deterioration may occur rapidly, and even infants who are not obviously in difficulties when first seen may die suddenly. Of the 53 infants in the present 
series, 17 were not investigated: some were moribund when first seen but others died while waiting for investigation. Some such wastage may be inevitable but its amount is related to the ease with which urgent catheterization procedures may be performed. Catheterization is ordinarily well tolerated even by ill newborn infants, provided hypoxia is minimized and hypothermia and excessive blood loss are avoided. Particular care must be taken to avoid ventilatory depression due to premedication. As the risk of error in clinical diagnosis of complete transposition is low, operation without preliminary study is justifiable if survival is clearly prejudiced by some unavoidable delay in performing investigation.

Anatomical and Hamodynamic Findings. The detailed anatomical findings in the group studied were as expected. Ventricular septal defects were demonstrated at necropsy in 13 patients and demonstrated by investigation in 4 others. There were thus 17 patients in 53 cases of complete transposition with ventricular septal defects. At least minor duct patency was common. Patency of the foramen ovale was an almost constant finding in those patients whose atrial septum had not been partly excised. These figures may be compared with an additional group of 35 heart specimens from infants with transposition, which were available in the files of the Pathology Department of the Royal Children's Hospital. Of these 35 specimens there were 10 with ventricular septal defect and at least 20 with some duct patency. All exhibited varying degrees of patency of the foramen ovale which was widely open in some. Three showed evidence of true atrial septal defect, but in each case these defects were tiny. In the 60 specimens of the series of Elliott et al. (1963) there were 22 with a defect of the ventricular septum, and 34 with duct patency. All had an interatrial communication, half being described as a valvular competent foramen ovale and half as a small atrial defect at the fossa ovalis.

It is impossible in the present series to correlate satisfactorily the duration of survival with the defects demonstrated and their hæmodynamic effects. Survival was affected by surgical intervention which was partly dependent for its timing on the onset of symptoms and partly on uncontrollable factors determining age of referral. Complete and final documentation of all defects is also not available. However, only 1 of 12 patients who died without operation in the first 2 weeks of life had a ventricular septal defect, this being associated with hypoplasia of the right ventricle and an interrupted aortic arch. Death was precipitated as previously stated by complications of investigation. On the other hand, while some patients deteriorated rapidly, others entered a stable but hypoxic state not dependent on the presence of a ventricular septal defect. Two infants were observed in such a state until the ages of 17 and 19 months before operation was performed, but neither of these had positive evidence of ventricular defects. The presence of a substantial ventricular defect is not necessary to prolong survival nor does it in fact guarantee a large effective pulmonary flow.

The hæmodynamic patterns of transposition are more important than the pure anatomical findings. Noonan et al. (1960) assessed shunting at various levels in considerable detail, but this did not prove possible in the present series. Further information is given by Shaher (1964). Noonan et al. were able to enter the pulmonary artery in 23 of 37 studies, but in the present series this was achieved on only 3 occasions. Although investigation became progressively more productive as the series advanced, the total information available is insufficient to justify more than brief comment. Atrial shunting was most commonly right to left, but was in some apparently absent and in one bidirectional. Left ventricular pressures were obtained in 10 patients. These suggested normal postnatal decrease in pulmonary vascular resistance. A systolic pressure equivalent to right ventricular (systemic) systolic pressure indicated substantial ventricular septal defect. Only one of the 3 patients so far subjected to follow-up catheterization has evidence of serious rise of pulmonary vascular resistance. The incidence of sufficient rise in pulmonary vascular resistance to contraindicate subsequent reparative surgery in patients who have required creation of an atrial septal defect in infancy is likely to be established only after further study of a substantial group of survivors.

It seems likely that the initial redistribution of blood between systemic and pulmonary circuits, which occurs in the neonatal period in complete transposition, and which is evident from the observed radiological changes, results from predominant shunting towards the pulmonary circuit in the phase of normal maximal postnatal duct patency. The distribution of blood must depend on relative resistances in the two circuits. The hæmodynamic situation in transposition stabilizes usually with smallish balanced shunts between the two parallel circuits constituting the effective pulmonary flow, but with a pulmonary flow often considerably greater than systemic flow (Shaher, 1964). Taussig (1960) suggested that there were rhythmic variations in the direction of the shunts in complete transposition, but observations of Vengsarkar and Swan (1964) on arterial saturations indicate a steady state in complete transposition without pulmonary stenosis, and support the presence of balanced shunts. 
Systolic shunts through a ventricular septal defect and shunting through a patent ductus will be determined by relative levels of pulmonary and systemic resistance unless the defects are small and govern shunting by their own local resistance. Atrial shunting depends on relative atrial pressures and in turn on pulmonary flow which indirectly determines left atrial pressure (Shaher, 1964). In a normal heart, increase in left atrial pressure resulting from increased pulmonary flow due to a large patent ductus may lead to considerable shunting from left to right atrium through a stretched foramen ovale (Rudolph et al., 1958). In complete transposition, this mechanism presumably permits the pure leftto-right shunting at atrial level, which balances right ventricular-pulmonary artery shunting or aortopulmonary shunting when a ventricular septal defect or patent ductus is associated with increased pulmonary flow. It also presumably accounts for the left-to-right component of bidirectional shunting at atrial level when a stretched foramen ovale is the only communication present between the systemic and pulmonary circuits. In these circumstances the foramen ovale functions as a true atrial septal defect, the important difference being the limitation of size of this defect compared to the usual true atrial septal defects of normal or surgical origin. A dilated foramen ovale may provide a larger shunt than small true atrial septal defects, but is unlikely to compare in size with the defect produced by adequate operation.

Management. The various operations which have been performed to alleviate complete transposition have been described by Baffes (1962). They include procedures producing both palliation and complete repair. Transfer of the transposed arterial trunks to their correct positions appears to be technically feasible (Baffes, 1962), but may be hæmodynamically unsatisfactory because the left ventricle is frequently not suited to carry a systemic load. Physiological total repair by diversion of the venous inflows through operations using cardiac tissue as in the Senning procedure (Senning, 1959), or using plastic patches (Merendino et al., 1957) or pericardial patches, appears to be more practicable and is successful in selected cases (Kirklin, Devloo, and Weidman, 1961; Aronstam et al., 1963; Mustard et al., 1964). The present series emphasizes the need for intervention at an age when poor tolerance of total body perfusion and difficulties of intracardiac manipulation render reparative procedures almost impossible. The principal palliative operations used have been the Baffes procedure, involving partial venous transposition (Baffes, 1962), and the creation of atrial septal defects mainly by closed techniques with or without pulmonary artery banding to reduce actual pulmonary flow (Blalock and Hanlon, 1950; Ochsner et al., 1961; Helmsworth et al., 1964; Schuster et al., 1963). The value of the creation of atrial septal defects has been demonstrated by Ochsner et al. (1961), and is confirmed by the present series. The over-all mortality in Cooley's patients (Ochsner et al., 1961) was 33 per cent, including 2 late deaths, in a series of 45 patients. The majority of his surviving patients had "significant and often striking symptomatic improvement". In the current series 15 of 30 patients were immediately improved, but 2 of these died within a few months, so that the effective salvage rate was in fact 13 of 30 operated cases. There has been a further death following an attempt at repair by diversion of venous inflow. The 4 survivors in whom no effective atrial defect appeared to have been created were operated on in the first 2 years of the study. Their ages at operation ranged from 3 weeks to 6 months. The oldest was operated on under inflow occlusion and the others by the Blalock-Hanlon technique. The minimum follow-up in the surviving improved patients is 14 months, the current clinical condition in all but one being satisfactory and stable. These results support the value of the procedure. The series does not provide its own controls, since continuing survival was an important factor in selection for operation. Only one patient was not operated on because of unsuitable hæmodynamics; the others died before operation could be performed. Nevertheless the occurrence of 13 long-term survivors $(24 \%)$ in an unselected series of 53 patients with complete transposition presenting in infancy compares favourably with the expected outcome without operation, while the current status of these survivors is much better than that seen in natural long-term survivors. Pulmonary artery banding was not employed in these patients, but there is evidence that cases of transposition, in which severe hypoxia is associated with a large actual pulmonary flow, benefit from the combined procedure of creation of an atrial septal defect and banding the pulmonary artery (Helmsworth et al., 1964; Glotzer, Young, and Bloomberg, 1963). Reduction of pulmonary flow decreases left ventricular loading and cuts down the risk of left ventricular failure.

Further investigation will be required to assess the hæmodynamic situation in survivors and to determine particularly changes in pulmonary vascular resistance and suitability for reparative operation. Uncertainty about the future inevitably aggravates the substantial parental anxiety attached to this condition, and it is necessary to minimize this as far as possible. It is not wise to encourage grouping 
of parents since identification with the problems and anxieties of others may well increase individual family loads undesirably. Management of this difficult problem is, however, facilitated by keeping parents well informed and providing adequate opportunity for discussion of problems.

\section{SUMMARY}

During the years 1960-63 inclusive, 53 infants with complete transposition of the great vessels were seen at the Royal Children's Hospital, Melbourne. Of these infants, 36 were investigated by venous angiocardiography or by cardiac catheterization with selective angiocardiography. An attempt was made to create an atrial septal defect in 30 infants, either under direct vision during inflow occlusion or by the technique of Blalock and Hanlon. There were 11 operative deaths and 15 infants appeared to be improved by the procedure. Of these improved survivors, 13 patients have been followed for up to 4 years with 1 death following an attempt at complete repair. The degree of improvement varied but most infants could be classified as having had good functional results. There is as yet insufficient evidence to gauge the likelihood of rising pulmonary vascular resistance in survivors. Various aspects of complete transposition of the great vessels in infancy are discussed in relation to the present series of cases.

The author is grateful to the members of the Senior Medical Staff of the Royal Children's Hospital, who have referred patients. As stated, the surgical procedures were performed by Mr. G. Westlake and by Mr. Peter Jones. Necropsies were carried out by the Department of Pathology of the Royal Children's Hospital, Melbourne.

\section{REFERENCES}

Aronstam, E. M., Hewlett, T. H., Orbison, J. A., Franklin, R. B., and Dixon, L. M. (1963). Surgical correction of transposition of the great vessels: A successful complete correction. Ann. Surg., 158, 282.

Astley, R., and Parsons, C. (1952). Complete transposition of the great vessels. Brit. Heart f., 14, 13.

Baffes, T. G. (1962). Current methods for surgical correction of transposition of the great vessels. Progr. cardiovasc. Dis., 4, 335.

Blalock, A., and Hanlon, C. R. (1950). The surgical treatment of complete transposition of the aorta and the pulmonary artery. Surg. Gynec. Obstet., 90, 1.

Elliott, L. P., Neufeld, H. N., Anderson, R. C., Adams, P., Jr., and Edwards, J. E. (1963). Complete transposition of the great vessels. 1. An anatomic study of sixty cases. Circulation, 27, 1105.
Glotzer, P., Young, D., and Bloomberg, A. (1963). Sequential banding and creating of atrial septal defect for transposition of the great vessels. $\mathcal{F}$. thorac. cardiovasc. Surg., 46, 104.

Helmsworth, J. A., Kaplan, S., Keirle, A. M., and Jones, D. V. (1964). Results of palliative and curative operations for transposition of aorta and pulmonary artery. Circulation, 29, Suppl. 1: Cardiovascular Surgery 1963, p. 114.

Keith, J. D., Rowe, R. D., and Vlad, P. (1958). Heart Disease in Infancy and Childhood. Macmillan, New York.

Kirklin, J. W., Devloo, R. A., and Weidman, R. A. (1961). Open intracardiac repair for transposition of the great vessels: 11 Cases. Surgery, 50, 58.

Merendino, K. A., Jesseph, J. E., Herron, P. W., Thomas, G. I., and Vetto, R. R. (1957). Interatrial venous transposition. Surgery, 42, 898.

Mustard, W. T., Keith, J. D., Trusler, G. A., Fowler, R., and Kidd, L. (1964). The surgical management of transposition of the great vessels. $\mathcal{F}$. thorac. cardiovasc. Surg., 48, 953.

Noonan, J. A., Nadas, A. S., Rudolph, A. M., and Harris, G. B. C. (1960). Transposition of the great arteries. A correlation of clinical, physiologic and autopsy data. New Engl. F. Med., 263, 592.

Ochsner, J. L., Cooley, D. A., Harris, L. C., and McNamara, D. G. (1961). Treatment of complete transposition of the great vessels with the Blalock-Hanlon operation. Circulation, 24, 51.

Rudolph, A. M., Mayer, F. E., Nadas, A. S., and Gross, R. E. (1958). Patent ductus arteriosus. A clinical and hemodynamic study of 23 patients in the first year of life. Pediatrics, 22, 892.

Schuster, S. R., Kiernan, E., Rosencranz, J., and Bozer, A. (1963). A new technique for the creation of an atrial septal defect with clinical application. F. thorac. cardiovasc. Surg., 46, 510.

Senning, A. (1959). Surgical correction of transposition of the great vessels. Surgery, 45, 967.

Shaher, R. M. (1963). Prognosis of transposition of the great vessels with and without atrial septal defect. Brit. Heart f., 25, 211.

- (1964). The hæmodynamics of complete transposition of the great vessels. Brit. Heart f., 26, 343.

Taussig, H. B. (1960). Congenital Malformations of the Heart, 2nd ed., Vol. 2: Specific Malformations. (The Commonwealth Fund), Harvard University Press, Cambridge, Mass.

Venables, A. W., and Campbell, P. E. (1966). Double outlet right ventricle. Brit. Heart $\mathcal{F}$. In the press.

$\longrightarrow$, and Hiller, H. G. (1963). Complications of cardiac investigation. Brit. Heart f., 25, 334.

Vengsarkar, A. S., and Swan, H. J. C. (1964). Variations in oxygen saturation of arterial blood in infants and children with congenital heart disease. Amer. F. Cardiol., 14,622 .

Wells, B. (1963). The sounds and murmurs in transposition of the great vessels. Brit. Heart f., 25, 748.

\section{ADDENDUM}

The condition of all survivors has shown no significant change up to the end of 1965. 